\section{PERIO \& CARDIO CAMPAIGN HIGHLIGHTS KEY MESSAGES}

Patients with gum disease should be told that they have a higher risk of suffering cardiovascular diseases - including myocardial infarction and stroke - and that they should actively manage risk factors such as smoking, lack of exercise, excess weight, blood pressure, and a diet high in saturated fats and refined sugars.

Patients who suffer from both periodontitis and cardiovascular disease may have a higher risk of cardiovascular complications and should carefully follow recommended dental regimes of prevention, treatment, and maintenance.

These are among the key messages of the Perio \& Cardio educational campaign launched on 15 September by the European Federation of Periodontology (EFP) and the World Heart Federation (WHF). This global initiative is centred on the perioandcardio. efp.org site, which contains recommendation documents, infographics, an animated film, and other educational materials - all aimed at bringing this knowledge to the dental team, cardiologists, medical professionals, pharmacists, and the public.

Perio \& Cardio is based on a new evidence-based scientific consensus on the links between periodontal and cardiovascular diseases and expert recommendations on prevention and therapy for both types of disease.

All the material in the campaign derives from the consensus report Periodontitis and cardiovascular disease ${ }^{1}$ - published in February by the EFP's Journal of Clinical Periodontology - which expressed the findings of the Perio-Cardio Workshop, held in Madrid in 2019, which brought together 20 world-leading experts in the fields of periodontology and cardiology.

For more information visit https:// www.efp.org/gum-disease-general-health/ perio-cardio/. $\checkmark$ Perio

Healthy gums

for a healthy heart

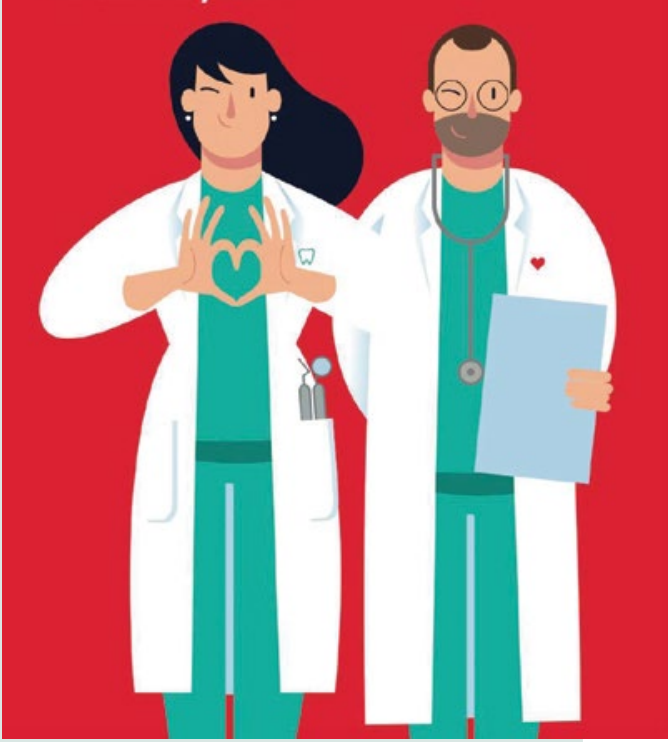

Reference

1. Sanz M, Del Castillo A M, Jepsen S et al. Periodontitis and cardiovascular diseases: Consensus report. J Clin Periodontol 2020; 47: 268-288.

\section{DENTAL TOUR ALL SET TO TREAT FISHERMEN IN CORNWALL AND DEVON}

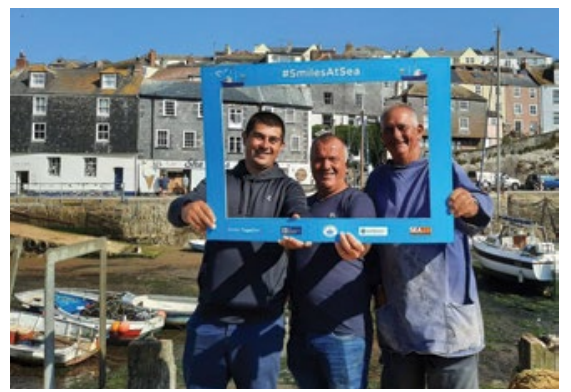

The SeaFit Programme is a joint initiative between highly respected national maritime charities, the Fishermen's Mission and the Seafarers Hospital Society, with funding from Seafarers UK. SeaFit has partnered with Smile Together to provide this free dental advisory service to local fishermen and their families across Cornwall and Devon.

Covering Cornwall and the Isles of Scilly, Smile Together are one of the South West's largest NHS referral and emergency primary dental care providers. Their West Country Dental Care team provide urgent and emergency dental treatments for people who don't have their own dentist, run out-ofhours surgeries and apply expert skills to treat children and adults with a range of special care needs alongside oral surgery, children's orthodontics and treatments under general anaesthetic in a hospital setting

This year's \#SmilesAtSea and SeaFit tour of Cornwall and Devon will be a little different due to COVID-19 regulations. Its focus will be on increasing fishermen and their families' knowledge and awareness of good oral health, along with reducing their sugar intake and changing their eating and toothbrushing habits to improve their dental health.

SeaFit Manager Carol Elliott said: 'We know how hard it can be to get to the dentist when you're out at sea and it's even more difficult at the moment, so we're bringing free dental advice and information to the harbourside instead. We've always been delighted with the response to this dental tour and many of the fishermen we've seen in the past hadn't seen a dentist for years, so knowing how to prevent the need for treatment is even more important now. We will be following local and national COVID19 guidelines to keep people safe and there's no need to book - just turn up!'

Starting with Newquay on 16 September, the tour will visit five other fishing ports: Newlyn, Mevagissey, Padstow, Plymouth and Brixham throughout September and October.

\section{NEVER MISS AN ISSUE OF BDJ TEAM}

Never miss an online issue of $B D J$ Team: sign up to our e-alert! Just click on this link to enter your details, and each time a new online issue of $B D J$ Team is published, the table of contents will be sent to your inbox: https:// go.nature.com/3iuZrKP.

$B D J$ Team is part of the $B D J$ Portfolio, and is published ten times a year by Springer Nature on behalf of the British Dental Association

(BDA). It also offers ten hours of free CPD each year through the BDA's CPD Hub.

To sign up for the $B D J$ Team e-alert, scroll down to 'Journal Tools' on the BDJ Team homepage at www.bdjteam.co.uk or follow this link: https:// go.nature.com/3iuZrKP.
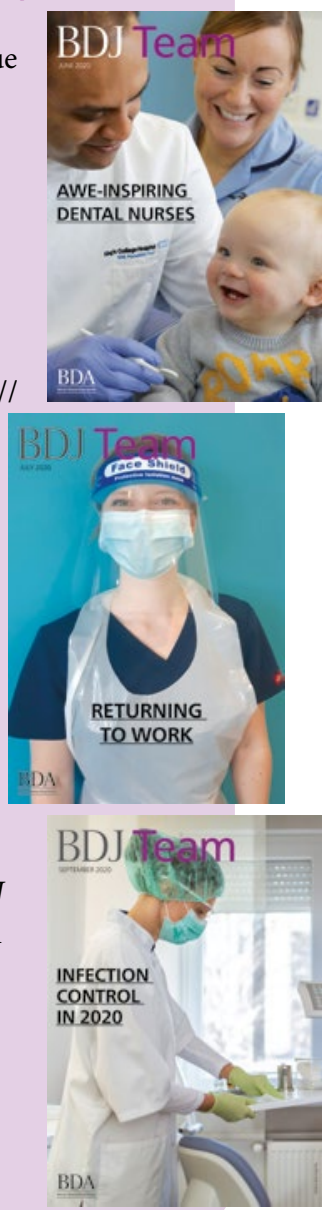